literature when I wrote my lecture"'

Fischer was convinced that bacteria are only saprophytic upon tissues already broken down and that they cannot penetrate undamaged cells. Smith quoted experiments showing how bacteria can dissolve cell walls and that they can enter undamaged tissues, for example pear blight bacteria can penetrate through nectaries. In the end nobody won as such. Smith died in 1927 after a long and distinguished career, and although Fischer eventually suffered from depression and committed suicide in 1913 his professional stature was not diminished by the controversy.

\section{IMAGE \\ UNAVAILABLE FOR COPYRIGHT REASONS}

Erwin Smith, farm boy turned plant pathologist. In 1899 he wrote of Fischer ". . . . he garbles and misrepresents, charging other men with being stupid blunderers...".

Nonetheless, the debate proved to be a significant event in plant pathology. Smith's view became accepted, and plant pathologists began to work seriously on bacterial diseases. Today between 180 and 200 species of plant pathogenic bacteria are recognized, causing serious economic loss throughout the world. They are unable to penetrate the plant cuticle and many require wounds to gain entry into the host plant but some enter through natural openings. Many are windblown or disseminated by splashing water, and at least 60 species can be carried by insects, for example fire blight of apples and related species is carried by honey bees.

The statements some of us make today are usually shorter but they are no more reasonable than those made by our predecessors. I can well remember the disbelief when it was first suggested that nematodes can carry virus diseases, and some of the diseases I thought to be caused by the viruses have been shown to be caused by mycoplasma-like organisms. Like so many controversies of the past, the Fischer-Smith debate repeats the lesson that in plant pathology, as in all of science, dogmatism is dangerous.

G.D. Heathcote is at Broom's Barn Experimental Station, Higham, Bury St Edmunds, Suffolk.

\title{
Test tube to womb: ethics and politics
}

\section{R.V. Short}

From Chance to Purpose: An Appraisal of External Human Fertilization. By Clifford Grobstein. Pp.207. ISBN 0-201-04585-0. (Addison-Wesley: 1981.) \$17.50, £11.50.

IN THIS book Dr Grobstein, Professor of Biological Science and Public Policy at the University of California, San Diego, seeks to describe for the general reader the technical procedures involved in human in vitro fertilization, and the social and political implications of this work. We are told that Dr Grobstein is internationally known for his research in developmental biology, and so we are entitled to expect a good read, and a penetrating analysis of present developments and future prospects.

The book turns out to be little more than an annotated commentary on the report of the US Ethics Advisory Board on Research Involving Human In Vitro Fertilization and Embryo Transfer, which was published in 1979. Fortunately this report is reprinted as an appendix, and for those not already familiar with it, it will form by far the most interesting part of Grobstein's book. Joseph Califano, the former Secretary of Health, Education and Welfare in the Carter administration, deserves considerable credit for setting up the Ethics Advisory Board, alas now disbanded, and charging such a distinguished group of scientists, lawyers, theologians, clinicians, ethicists and administrators with an in-depth investigation of the whole subject of in vitro fertilization. The way the Board went about this task was commendable. They commissioned manuscripts from leading experts known to have views on the matter, and held public hearings around the United States, with live radio and television coverage, to which anyone could give testimony, and at which the experts were cross-questioned by the Board. All the written evidence was then published, together with the incisive, common-sense judgements of the Board, who must have been greatly indebted to their chairman, a lawyer, James C. Gaither, for producing a consensus report from a Board that itself embraced such widely divergent views. The conclusions were neither remarkable nor controversial. The human embryo is entitled to profound respect, but this does not necessarily encompass the full legal and moral rights attributed to an adult individual. Therefore, a broad prohibition of research involving human in vitro fertilization is neither justified nor wise. Federal support for such work would be ethically acceptable, and there is a need for more research in order to assess the risks to mother and offspring.

The Board managed to steer a course between the Scylla of those such as the President of the Massachusetts Council of
Rabbis, who thundered that "Further in vitro experimentation could tend to eliminate the need for the human family and turn humanity into a zoo of fertilized and fertilizing animals", and the Charybdis of the brothers Seed (sic) who offered to buy fertilized eggs flushed from the uteri of women donors, and transfer them to the uteri of infertile recipients - at a price. Nevertheless, the publication of the Board's findings in the Federal Register on June 19th 1979 produced a storm of written protest from, one suspects, the Right to Life group. Secretary Califano took no action on the Report's recommendations, and shortly thereafter resigned. The Ethics Advisory Board was then disbanded because Congress established a new "President's Commission for the Study of Ethical Problems in Medicine and Biomedical and Behavioral Research', that does not seem to have addressed itself to the problem, and America changed Presidents.

Since that time, nothing more has been heard of the Board's report. It seems to have sunk without trace, presumably too hot for a right-wing administration to handle. But thereby went an honest attempt to reach a consensus view by public debate of a contentious issue, and much time and money was wasted in the process. It is sobering for scientists to realize that even if an issue is scientifically, socially and ethically acceptable, it will receive no governmental support unless it is politically expedient. But Everyman will have the last say; new clinics are opening up around the world, and the number of successful births following in vitro fertilization is now into the teens. Even the President of the United States cannot halt such progress, although the paucity of governmental funding for the back-up research that is so urgently needed can significantly delay it. The success rate of the procedure is still very low, and research could surely improve it to the point where we might expect a 25 per cent chance of pregnancy following embryo transfer, which is the probability that a fertile woman has of conceiving in an ordinary menstrual cycle.

But all of these comments relate to the appendix. What of the book itself? It has little to add that is new, much that could have been discussed is missing, and several statements are factually incorrect. As for its good points, it is sensible to suggest that we should re-name in vitro fertilization "external fertilization", a term that is infinitely preferable to "test-tube baby", which has alas probably come to stay. Grobstein also has an interesting chapter on "Becoming a Person", in which he propounds the common-sense view that "neither life nor the human quality begins in any generation. Human life, like that of all species, descends without break from 
generation to generation. It waxes and wanes in complexity but never begins de novo"'. But he has an ungainly style of writing: talking of human attributes, he says "As a group they span the biological, behavioral, and social realms, constituting a kind of slope between animal and human states along which our species has moved evolutionarily and continues to cycle generationally",

Although there is much discussion about "circumventing the oviduct", a valuable opportunity is missed by failing to compare this with "circumventing the penis"; the ethics of artificial insemination, whether by donor or husband's semen, have been widely discussed in recent decades. On the technical side, it is disappointing to find no mention of ultrasound, which is now widely used as a non-invasive way of monitoring follicular development. There is no discussion of interspecific fertilization, and yet use of denuded hamster oocytes to bioassay the fertilizing capacity and examine the karyotype of human spermatozoa has been an exciting recent technical advance, one which still seems to send an ethical shudder through the World Health Organization.

As for the mistakes, how unfortunate to depict luteinizing hormone as a secretory product of the posterior pituitary gland; how naive to believe that infertility in men is often the result of a low sperm count, so that merely increasing sperm density by centrifuging a semen sample will increase fertility. Recent evidence from hamster oocyte preparations shows quite clearly that oligospermic men are infertile because of some basic defect that results in the ejaculation of small numbers of spermatozoa each of which has a significantly reduced fertilizing potential; concentrating the ejaculate is therefore a waste of time. And Edwards and Steptoe, who after all pioneered this whole field, will be interested to hear that the work was done at Oldham Hospital in Cambridge, England! Not a book to recommend.

R.V. Short is Director of the MRC Unit of Reproductive Biology, Edinburgh.

\section{Lessons for twentieth-century nutritionists}

\section{John Rivers}

\author{
Nutrition and Nutritional Diseases: The \\ Evolution of Concepts. By Karl Y. \\ Guggenheim. Pp.378. ISBN 0-669-03950-0. \\ (Collamore Press, Massachusetts: 1981.) \\ $\$ 21.95$.
}

Although this is an important book, it must be admitted at the outset that it is not a historian's history. Professional historians of science will no doubt be irritated by the brevity with which many subjects are necessarily treated and by the occasional lapses that suggest historical naivety (for example, calling Boyle's school "Eaton", or seeming to equate Pereira's training as an apothecary with pharmacy not medicine).

But whatever its reception by historians, nutritionists will I hope buy and read this book, for it is an important history of their discipline and their profession, and one that they should study. It is all the more valuable because Professor Guggenheim is not a trained historian, but a nutritionist who, after a lifetime of research into the practical problems of nutrition, has produced this scholarly work in his retirement.

The discipline of nutrition is an uneasy coalition. Its scientific roots are in aspects of physiology which had their heyday in the nineteenth and the first half of the twentieth centuries. Its justification is a wide spectrum of unresolved practical problems, from tooth decay to the world food problem. And nutritionists, it must be admitted, are people who, by and large, fail either to revive the science or solve the problems to which it is addressed. As long as it is possible to imagine that, even if the next experiment won't save the starving masses at a stroke, it is a step in that direction, then there is an excuse for surfing along on the wave-front of the present. But as it increasingly appears that poverty not protein is the key to malnutrition, and that tooth decay can only be cured by drawing the teeth of the confectionery industry, the nutritionist increasingly needs to take stock and decide whether he is really necessary.

Individual action is of course irrelevant. What is needed is a dialogue within and beyond the profession about the extent to which nutritional science should be coupled to practical policy. Such a discussion would need to be guided by a coherent view of the past, and without the historian's spotlight can probably never begin. It is self-evident that such historical studies on nutrition as exist at present have not had any such catalytic role - not surprisingly, for where they are not social histories of diet, they are catalogues of achievements of the great and famous.

The significance of Professor Guggenheim's new book is that it is free of that tradition and hopefully will have a powerful impact. He does not merely retell the story of the development of the science of nutrition, but, more than any other work on the subject, he studies its growth mechanisms. His avowed aim is contained in the subtitle - he tries to trace "the evolution of concepts". He does so with great fluency, and in a way that is realistic, in that it sees the concept as dominating the fact. Moreover, he makes his account relevant to today's problems by devoting a large part of the book to focusing "attention on the conceptual evolution of five principal issues that . . . dominate nutritional thinking until our own time". In doing so he has chosen well, and his discussions on the concept of an adequate diet, on protein and on the origins of the dietary thermogenesis controversy (recently revived in Nature) are all very valuable.

I am slightly disappointed by the fact that, inasmuch as he looks beyond internal imperatives for the growth of nutritional science, his horizon is the parallel growth of ideas in other areas of science. Highlighting this feedback is valuable, and he provides the best discussion of such interactions that is available in a popular work. But it is a pity that he did not extend his view and concentrate more on general social history and the extent to which nutritional science was also moulded by the general ethos of the society in which it was developed. In his failure to do so, his work raises questions it cannot answer. For example, his treatment of the evolution of concepts of protein and energy metabolism in the nineteenth century, while meticulous and well worth reading, is for me incomplete. I cannot believe that the subject can be fully explored without discussion of the social values that predicted it, stimulated both the research and its acceptance, and dictated its conceptual framework. Nutrition developed in the new Europe where both workhouse and standing army grew up, and the state required dietetic advice on subsistence requirements for the poor, and optimal provision for its fighting men.

It is surely no coincidence that in this environment nutritionists adopted models which involved the idea that both minimal

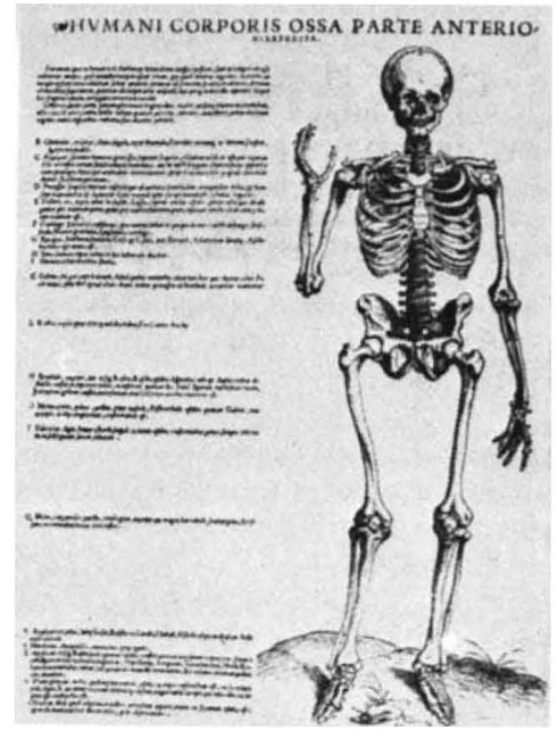

Skelcton of a rachitic male, depicted by $\mathrm{A}$ Vesalius in Tabulae Anatomicae Sex (1538). Rickets was apparently so prevalent that Vesalius regarded the skeleton, of an adult with late rickets, as normal. 